\title{
Palladium Nanoparticles Supported on Layered Hydroxide Salts and their Use in Carbon-Carbon Coupling Organic Reactions
}

\author{
Maby Martínez, ${ }^{a}$ Rogelio Ocampo, ${ }^{a}$ Luz Amalia Rios, ${ }^{a}$ Alfonso Ramírez $z^{b}$ and Oscar Giraldo ${ }^{*, c, d}$ \\ ${ }^{a}$ Departamento de Química, Universidad de Caldas, Calle 65 No. 26-10, Manizales, Colombia \\ ${ }^{b}$ Grupo de Catálisis, Universidad del Cauca, Calle 5 No. 4-70, Popayán, Colombia \\ ${ }^{c}$ Laboratorio de Materiales Nanoestructurados y Funcionales, Carrera 27 No. 64-60, \\ Manizales, Colombia \\ ${ }^{d}$ Departamento de Física y Química, Universidad Nacional de Colombia sede de Manizales, \\ Carrera 27 No. 64-60, Manizales, Colombia
}

\begin{abstract}
Nanopartículas de paládio suportadas em hidroxissal lamelar foram preparadas pela intercalação de $[\mathrm{PdCl} 6]^{2-}$ seguida pela redução com etanol sob condições de refluxo. Os materiais foram caracterizados por espectroscopia de absorção atômica (AAS), difração de raios X (XRD), análises termogravimétrica e térmica diferencial (TG/DTG), microscopia eletrônica de varredura (SEM), espectrometria UV-Visível e microscopia eletrônica de transmissão (TEM). A análise por TEM confirma a obtenção de nanopartículas suportadas. O material contendo nanopartículas de Pd foi utilizado em reações de acoplamento de Heck e Suzuki a partir de haletos de arila com rendimentos de 98, 75 e 62\% para a obtenção de bifenilo, ácido cinámico e 3-nitrobifenilo, respectivamente.
\end{abstract}

Palladium nanoparticles supported on zinc hydroxide salts were prepared by intercalation of $\left[\mathrm{PdCl}_{6}\right]^{2-}$ and its further reduction with ethanol under reflux. All the materials were completely characterized by atomic absorption spectroscopy (AAS), X-ray diffraction (XRD), thermogravimetric/derivative thermogravimetric (TG/DTG) analyses, scanning electron microscopy (SEM), UV-Visible spectrometry and transmission electron microscopy (TEM). TEM analysis confirmed that the palladium nanoparticles were properly supported. The material containing supported palladium nanoparticles was used to promote Heck and Suzuki coupling reactions starting from aryl halides, with isolated yields of 98,75 and $62 \%$ of biphenyl, cinnamic acid and 3-nitrobiphenyl, respectively.

Keywords: zinc hydroxide salts, palladium nanoparticles, Heck reactions, Suzuki reactions, hexachloropalladate

\section{Introduction}

Layered materials are very important entities especially because they offer an interesting possibility to host both organic and inorganic species in their interlayer spacing, including polymers and biomolecules. In this situation, the layered materials confer them particular physical and chemical properties which make the materials very attractive for applications such as catalysts, ${ }^{1}$ supporting materials, ${ }^{2}$ adsorbents, ${ }^{3}$ and anion exchange agents, ${ }^{3}$ UV absorption materials, ${ }^{4}$ electrodes, ${ }^{5}$ sensors,${ }^{6}$ optical

\footnotetext{
*e-mail: ohgiraldoo@unal.edu.co
}

materials, ${ }^{7}$ systems for safe and controlled delivery of substances and medical applications in general. ${ }^{8-10}$

For these purposes, little attention has been paid to layered hydroxide salts (LHS) with general formula $\mathrm{M}^{2+}(\mathrm{OH})_{2-\mathrm{x}}\left(\mathrm{A}^{\mathrm{m}-}\right)_{\mathrm{x} / \mathrm{m}}$ (with $\mathrm{M}^{2+}$ being a metallic cation and $\mathrm{A}^{\mathrm{m}-}$ the interlaminar anion). ${ }^{11,12}$ For the case of layered zinc hydroxide acetate, it has been determined that this compound has the hydrozincite-type structure, in which cations are located in both octahedral and tetrahedral sites and the acetate ions are intercalated as free anions. ${ }^{13}$

On the other hand, palladium is a versatile agent in the catalysis for a number of organic reactions, ${ }^{14-19}$ and this feature has called attention to explore its applications under 
nanometric dimensions both supported and non-supported..$^{20-23}$ It is well known that nanometric arrays confer a high catalytic efficiency to the materials because of their high surface:volume ratios. Several reports have demonstrated the potential of nanometric palladium particles in carboncarbon coupling reactions, ${ }^{15,22-24}$ which are important useful procedures for the synthetic organic chemistry, ${ }^{25,26}$ with their products becoming key intermediates for the preparation of other organic materials, ${ }^{27-29}$ natural products ${ }^{30}$ and bioactive compounds, ${ }^{31,32}$ such as taxol (antitumor agent) or cinnamic acid derivatives. ${ }^{33}$ These products exhibit antibacterial or antifungal activities and some other are useful as ingredients for fragrances. ${ }^{34,35}$ The biphenyl systems are particular kinds of products that derive from coupling reactions and are acknowledged as precursors for the preparations of analgesics and other pharmaceuticals. ${ }^{36}$

This article reports the synthesis and characterizations of palladium nanoparticles supported on layered materials (zinc hydroxide acetate) by anionic exchange with $\mathrm{K}_{2} \mathrm{PdCl}_{6}$ and its further reduction through the hosted complex with ethanol under reflux. The resulting solid was explored in preliminary tests to promote carbon-carbon coupling reactions starting from aryl halides, giving rise to biphenyl, cinnamic acid and 3-nitrobiphenyl with yields up to 98, 75 and $62 \%$, respectively.

\section{Experimental}

All chemicals (Sigma-Aldrich, 98 and 99\% purify) were used without further purification. The synthesis of supported palladium nanoparticles was performed in three steps: ( $i$ ) preparation of the zinc precursor and hydroxide acetate (LHS), (ii) anionic exchange of LHS with $\mathrm{K}_{2} \mathrm{PdCl}_{6}$ to produce (LHS60) and (iii) generation of Pd nanoparticles $\left(\mathrm{LHS}-\mathrm{Pd}^{0}\right)$ by reduction of the hosted $\left[\mathrm{PdCl}_{6}\right]^{2-}$ complex with ethanol under reflux.

\section{Synthesis}

\section{Synthesis of supporting LHS}

Zinc hydroxide acetate precursor (LHS) was prepared according to the literature by mixing together $\mathrm{ZnO}$ $(5.04 \mathrm{mmol})$ and $\mathrm{Zn}(\mathrm{OAc})_{2} \cdot 2 \mathrm{H}_{2} \mathrm{O}(6.91 \mathrm{mmol})$ in $10 \mathrm{~mL}$ of water at room temperature, while stirring for $24 \mathrm{~h}^{20}$ The material was centrifuged three times and washed with distilled, deionized water (DDW) and dried at room temperature. The material was labeled LHS.

\section{Intercalation of $\left[\mathrm{PdCl}_{6}\right]^{-2}$ anion}

$0.5 \mathrm{~g}$ of LHS was mixed and stirred with $50 \mathrm{~mL}$ of an aqueous solution of $\mathrm{K}_{2} \mathrm{PdCl}_{6}$ containing a palladium equivalent of $1.2 \mathrm{mg} \mathrm{mL}^{-1}$. Precaution was taken to run the reaction under inert $\mathrm{N}_{2}$ atmosphere in order to prevent the generation of carbonates that might derive from reaction of the materials with atmospheric $\mathrm{CO}_{2}$. After $24 \mathrm{~h}$ of reaction, the resulting material was centrifuged three times and washed with distilled, deionized water (DDW) and dried at room temperature. The material was labeled as LHS60.

\section{Preparation of LHS supported palladium nanoparticles}

LHS supported Pd nanoparticles were prepared according to the reduction method reported by Rajamathi et al. ${ }^{37}$ as follows: $0.2 \mathrm{~g}$ of the intercalated material LHS60 were suspended in $5 \mathrm{~mL}$ of ethanol and refluxed for $3 \mathrm{~h}$ with continuous stirring. The resulting material was finally centrifuged and washed three times with ethanol. The black solid was dried at room temperature and labeled as LHS-Pd ${ }^{0}$.

Preliminary carbon-carbon coupling reactions using LHS-Pd $d^{0}$

All the Suzuki and Heck reactions were run with $10 \mathrm{mg}$ of $\mathrm{LHS}-\mathrm{Pd}^{0}$ at $100{ }^{\circ} \mathrm{C}$ with the indicated organic starting materials under reflux and monitoring by thin layer chromatograph (TLC) (with hexane:ethyl acetate binary systems as eluent). After worked-up, the respective melting points of the organic products were determined in a Buchi-510 instrument and reported without correction. ${ }^{1} \mathrm{H}$ and ${ }^{13} \mathrm{C} \mathrm{NMR}$ spectra (in $\mathrm{CDCl}_{3}$ ) were run in a Bruker ARX-250 instrument and the signals were directly compared with the literature data, proving the identity of the expected products.

\section{Suzuki reactions}

Biphenyl was prepared by reaction of iodobenzene (3.0 mmol) with boronic acid $(4.2 \mathrm{mmol})$ in the presence of $\mathrm{KOH}(9 \mathrm{mmol})$ in $15 \mathrm{~mL}$ of a binary 5:1 mixture (v/v) dioxane:water. The coupled product was purified by flash column chromatography (silica gel 60 Merck as the stationary phase). An analog reaction was also performed in order to prepare 3-nitrobiphenyl by using $m$-nitroboronic acid instead of boronic acid, under identical reaction conditions.

\section{Heck reactions}

Cinnamic acid was prepared starting from iodobenzene $(8.04 \mathrm{mmol})$ and acrylic acid $(6.13 \mathrm{mmol})$ in the presence of triethyl amine $(12.5 \mathrm{mmol})$ in acetonitrile $(2 \mathrm{~mL})$. The reactant mixture was cooled down to room temperature and transferred into a beaker containing $50 \mathrm{~mL}$ of $3.0 \mathrm{~mol} \mathrm{~L}{ }^{-1} \mathrm{HCl}$. The resulting solid was filtered and washed with distilled, deionized water (DDW). 


\section{Physicochemical characterization of the inorganic materials}

All materials (LHS, LHS60 and LHS-Pd ${ }^{0}$ ) were characterized by atomic absorption spectroscopy (AAS), $\mathrm{X}$-ray diffraction (XRD), thermogravimetric/derivative thermogravimetric (TG/DTG) analyses, scanning electron microscopy (SEM), UV-Visible spectrometry and transmission electron microscopy (TEM).

For XRD analysis, a Rigaku Miniflex II instrument ( $30 \mathrm{kV}$ and $15 \mathrm{~mA}$ ) was used with $\mathrm{CuK}_{\alpha}$ radiation source with a scan rate of $2^{\circ} \mathrm{min}^{-1}$ in normal environmental conditions. The crystal size of Pd in the LHS-Pd ${ }^{0}$ was estimated from its diffraction pattern by the Debye-Scherrer's method. ${ }^{38}$

SEM was recorded in a JEOL5910 LV instrument with secondary electron detector, while transmission electronic microscopy was run in a JEOL 1200 EX instrument. TG/DTG analyses were recorded in a TA Instruments Q500 instrument with a heating rate of $10{ }^{\circ} \mathrm{C} \mathrm{min}-1$ under $\mathrm{N}_{2}$ atmosphere.

AAS was performed on a Perkin Elmer 3110, whereas UV-Vis analysis was recorded in a Lambda 20 instrument. The amount of metal palladium that was being retained inside the layered material was measured by UV-Vis after the construction of a preliminary calibration curve from the absorbance of standard solutions of $\mathrm{K}_{2} \mathrm{PdCl}_{6}$ in aqua regia. For this purpose, weighted samples of LHS-Pd ${ }^{0}$ were also dissolved in properly measured volumes of aqua regia and the absorbance data were recorded for the resulting solutions, so the amount of palladium was determined by direct comparison with the calibration curve.

\section{Results and Discussion}

Zinc hydroxide acetate LHS was initially prepared under mild reaction conditions (as described in experimental section). In this precursor, the acetate groups being localized in the interlayer space were exchanged with $\left[\mathrm{PdCl}_{6}\right]^{2-}$, and the resulting material LHS60 was reduced in ethanol under reflux, giving rise to a dark-colored solid LHS-Pd ${ }^{0}$.

This later material proved to contain supported palladium nanoparticles. From the reflection plane (111) of palladium, it was estimated a diameter of $7.4 \mathrm{~nm}$ for the palladium nanoparticles by the Debey-Scherrer's equation. $^{38}$

LHS- $\mathrm{Pd}^{0}$ material exhibited evidences of the presence of chloride anions that were released during the reduction procedure. The present authors suggest that chloride anions contribute to balancing the charge of the material forming a fraction of zinc hydroxide chloride. A content of $2.33 \%$ of chloride was determined by Morh's method. ${ }^{38}$ In fact, zinc hydroxide chloride phase as well was found in the XRD patterns (being described later). In comparison to zinc hydroxide acetate, the zinc hydroxide chloride has a different structure, and since the chloride anions in this case are not exchangeable, the layers bear no net charge.

Also, a content of palladium of $11.5 \%$ in LHS60 and $13.3 \%$ in LHS-Pd ${ }^{0}$ was determined by UV-Vis spectrometry. The difference of $1.8 \%$ of palladium content between these samples is in agreement with an expected increment of the relative abundance of palladium in the $\operatorname{LHSPd}^{0}$ material after the hexachloropalladate complex has released the chlorine atoms out from the layered material LHS60 during the course of the reduction. This suggests that no palladium leaching occurred along the reduction step.

The overall zinc content in the materials was determined by atomic absorption spectrometry, with the resulting of $49 \%$ of zinc for LHS, $46 \%$ for LHS60 and 47\% for LHS-Pd ${ }^{0}$. As expected, a higher content of zinc (49\%) was found for the LHS precursor. Slightly lower data (46 and 47\%) were found in LHS60 and LHS-Pd ${ }^{0}$, respectively. This is due to the insertion and modification of the palladium species in the exchange and reduction reactions.

The XRD diffraction pattern for the precursor is showed in Figure 1d. Figures 1b and 1c correspond to the diffraction pattern of the reactants and reveal the generation of a pure phase of the layered hydroxide salt. Figure 1d clearly exhibits two peaks that correspond to the basal spacing 20.6 and $13.8 \AA$, indicating the presence of two phases. It is common to find procedures in the literature that are similar to the one which the present article reports for the synthesis of this type of materials, ${ }^{1,39,40}$ giving rise to a

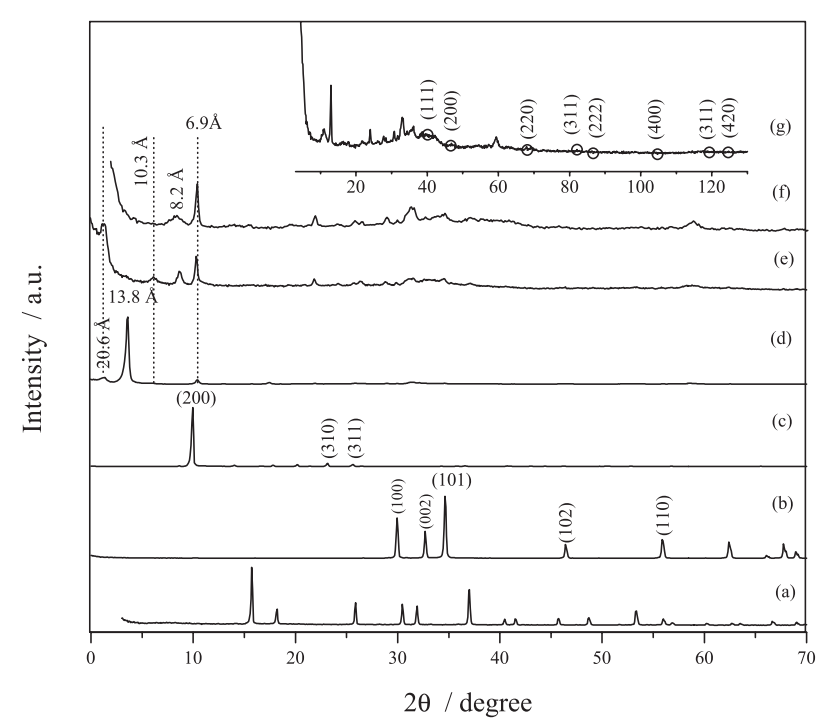

Figure 1. XRD patterns of (a) $\mathrm{K}_{2} \mathrm{PdCl}_{6}$, (b) $\mathrm{ZnO}$, (c) $\mathrm{Zn}(\mathrm{OAc})_{2}$, (d) zinc hydroxide acetate (LHS), (e) LHS60, (f) LHS-Pd ${ }^{0}$ and (g) characteristic peaks for $\mathrm{Pd}^{0}$ in LHS-Pd ${ }^{0}$. 
layered hydroxide salt phase with a unique basal spacing ranging in the interval of 13.2-13.4 $\AA$. In our case, however, the observed basal spacing is $13.8 \AA$.

The second reflection peak of $20.6 \AA$ is similar to the one reported by Song et al. ${ }^{41}$ who prepared a bilayered zinc acetate salts (a BLBZA nanobelt-type material, $\left(\mathrm{d}_{001(\mathrm{I})}=13.3 \AA\right.$ and $\mathrm{d}_{001(\mathrm{II})}=20.3 \AA$ ) starting from $\mathrm{Zn}(\mathrm{OAc})_{2}$ and ammonia at $30-60{ }^{\circ} \mathrm{C}$ by hydrothermal treatment for $12 \mathrm{~h}$. In the present study, it was obtained a similar material but our procedure involves milder conditions as room temperature and atmospheric pressure. It is suggested that the small difference in the reported basal spacing might result from slightly different extents of hydration of the layered hydroxide salt.

For the exchanged and the reduced materials (LHS60 and LHS-Pd ${ }^{0}$, respectively), XRD patterns are shown in Figure 1d-f. From these figures, it is evident that the materials give raise to different patterns each other. This proves that it took place some transformation. It is clearly observed that upon intercalation of $\left[\mathrm{PdCl}_{6}\right]^{2-}$ in the interlayer space of the LHS material only the phase of $20.6 \AA$ is kept. This result suggests a good interaction between support and the hosted anion $\left[\mathrm{PdCl}_{6}\right]^{2-}$ and its homogeneous distribution in the material. Although the final reduced material that was obtained thereafter does not exhibit the original spacing characteristic of the LHS precursor. This is induced by the formation of palladium nanoparticles of different sizes ranging from 6 to $13 \mathrm{~nm}$, as deduced from TEM image (Figure 2). This size turns out to be in a close agreement with the crystal size of $7.4 \mathrm{~nm}$ for the nanoparticles that was estimated from the Debey-Scherrer equation, ${ }^{38}$ by using the (111) reflection plane of the Pd XRD pattern (Figure 1g).

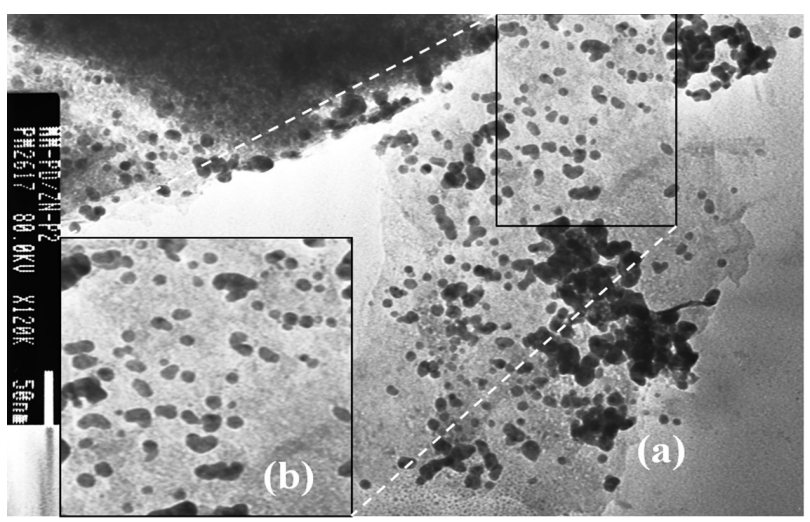

Figure 2. TEM images of (a) LHS-Pd ${ }^{0}$ and (b) zoom of the marked area in (a).

On the other hand, by using the diffraction pattern of the reduced material and matching with crystallographic data from the literature, it was confirmed the formation of a new layered hydroxide salt assigned to zinc hydroxide chloride of formula $\mathrm{Zn}_{5}(\mathrm{OH})_{8} \mathrm{Cl}_{2} \cdot \mathrm{H}_{2} \mathrm{O}, \mathrm{d}=8.2 \AA$ (Figure 1f). ${ }^{42}$ This reaction involves the formation of $\mathrm{ZnO}$ as well and this inorganic product certainly results from the decomposition of part of the laminar structure, as evidenced upon comparison of Figures $1 \mathrm{~b}$ and 1f. Crystallographic planes of metal palladium in a cubic system and spatial group Fm3m are presented in Figure 1g. ${ }^{43}$ Finally the distance at $\mathrm{d}=6.9 \AA$ (Figure 1) may be assigned to the second reflection of the $13.8 \AA$ phase and also to the third reflection corresponding to the $20.6 \AA$ phase. The TG/DTG plots for the reduced material and its precursors are observed in Figure 3, evidencing a total weight loss of 36, 25 and 21\%, respectively for LHS, LHS60 and LHS-Pd ${ }^{0}$ (Figure 3d-f). All materials exhibit several decomposition steps which are also observed in other anionic clays. ${ }^{44}$

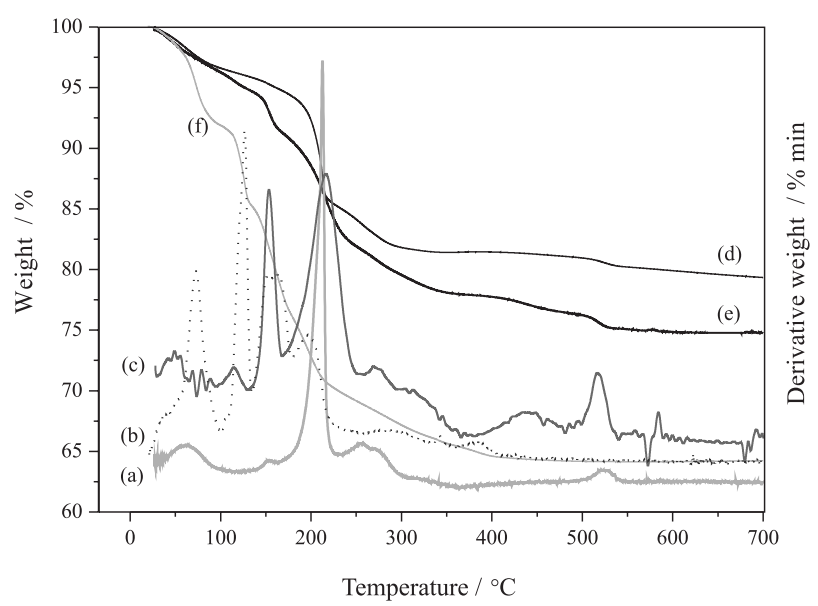

Figure 3. DTG curves of (a) LHS-Pd ${ }^{0}$, (b) zinc hydroxide acetate (LHS) and (c) LHS60 and TG curves of (d) LHS-Pd ${ }^{0}$, (e) LHS60 and (f) zinc hydroxide acetate (LHS).

The first weight loss may be explained by the release of physisorbed and interlayer waters, which starts at room temperature and is completed at 110,140 and $180{ }^{\circ} \mathrm{C}$ in LHS, LHS60 and LHS-Pd ${ }^{0}$, respectively, in agreement with 9,5 and $6 \%$ of weight loss in each case. A second thermal event that is completed at $400^{\circ} \mathrm{C}$ has been mainly assigned to dehydroxylation of the laminar structure and the decomposition of acetate groups which are occupying the interlayer space. It is noteworthy that the starting temperature for dehydroxylation $\left(110,140\right.$ and $180^{\circ} \mathrm{C}$ for LHS, LHS60 and LHS-Pd ${ }^{0}$, respectively) is consecutively higher in going from the exchanged material to the reduced one. With this observation in mind, it is possible to conclude that the intercalation and reduction reactions enhance the thermal stability of the material. Beyond $400{ }^{\circ} \mathrm{C}$, no important changes are observed in the LHS precursor, although the exchanged and reduced materials exhibit a 
third thermal event that is completed at about $500{ }^{\circ} \mathrm{C}$. This later thermal event may be attributed to a loss of chloride anion from the hexachloropalladate complex of LHS60 (in the case of the exchanged material). Likewise, the analog thermal event for the reduced LHS-Pd ${ }^{0}$ material is due to a release of chloride anion that was produced in the course of the reduction step for a balance of charge in the layers of material. The presence of chloride in these materials was quantitatively confirmed by Morh's method. ${ }^{38}$

The SEM images of LHS precursor (the exchanged LHS60 and the reduced LHS-Pd ${ }^{0}$ materials) are presented in Figure 4.

As clearly observed in Figure 4a, zinc hydroxide acetate exhibits a flake like, slightly rough morphology, which is the typical surface appearance of layered materials. ${ }^{44}$ This morphology is not observed anymore after $\left[\mathrm{PdCl}_{6}\right]^{2-}$ intercalation took place, as it is in fact observed for the LHS60 material in Figure 4b, whose morphology becomes more compact with small clusters on the surface. Additional morphological changes with larger clusters are observed as well in the reduced material, as evidenced in Figure 4c.

Transmission electronic microscopy TEM was used as a tool to detect de presence of palladium nanoparticles in the reduced material labeled as LHS-Pd ${ }^{0}$. TEM images (Figure 2) confirmed that palladium was in fact reduced by refluxing ethanol from the $\mathrm{Pd}(\mathrm{IV})$ state of $\left[\mathrm{PdCl}_{6}\right]^{2-}$ to $\mathrm{Pd}^{0}$, giving rise to particles with sizes ranging from $6-13 \mathrm{~nm}$, as evidenced in the magnified TEM image (Figure 2b). Larger particles are also observed in Figure 2, probably resulting from primary particle agglomerations.

The reduced LHS- $\mathrm{Pd}^{0}$ material was then used in preliminary tests to promote carbon-carbon coupling reactions and the results are presented in Table 1. Several previous works have explored the synthesis of biphenyl

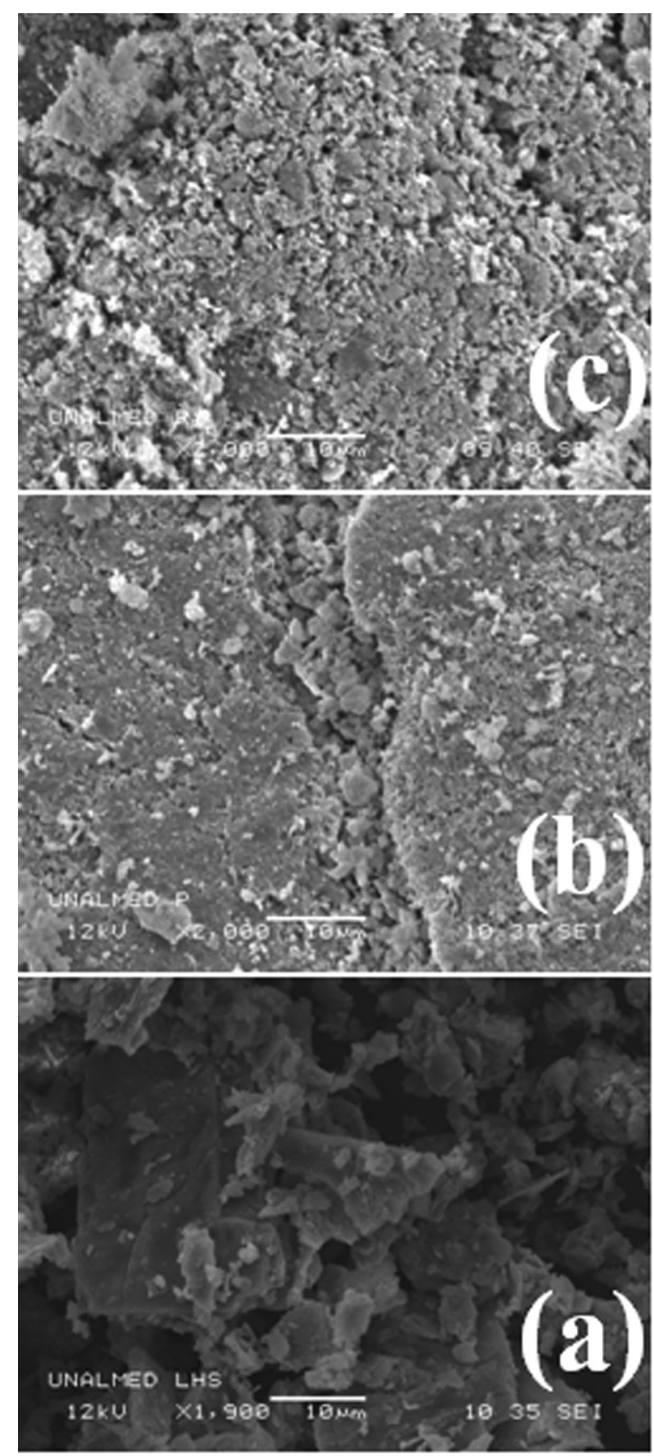

Figure 4. SEM images of (a) zinc hydroxide acetate (LHS), (b) LHS60 and (c) LHS-Pd ${ }^{0}$.

Table 1. Results of Heck and Suzuki reactions

Coupling reaction

Heck reactions: iodobenzene $(8.04 \mathrm{mmol})$, acrylic acid $(6.13 \mathrm{mmol})$, triethyl amine $(12.5 \mathrm{mmol}), \mathrm{LHS}-\mathrm{Pd}^{0}(10 \mathrm{mg})$ and $2 \mathrm{~mL}$ of acetonitrile, at $90-100{ }^{\circ} \mathrm{C}$ under reflux; Suzuki reaction: iodobenzene $(3.0 \mathrm{mmol})$, boronic acid $(4.2 \mathrm{mmol}), \mathrm{KOH}(9 \mathrm{mmol}), \mathrm{LHS}-\mathrm{Pd}^{0}(10 \mathrm{mg})$ and $15 \mathrm{~mL}$ of a $5: 1 \mathrm{v} / \mathrm{v}$ binary mixture 1,4-dioxane:water, at $100{ }^{\circ} \mathrm{C}$ under reflux. 
systems with good to high yields promoted by palladium nanoparticles supported on polyacrylamide with $96 \%$ yields. ${ }^{19}$ Similar results (95\% yields) have been reported when using diatomaceous supports, ${ }^{45}$ organostannoxane (with reported yields of up 99\%) (6) $^{46}$ and layered double hydroxides LDH (with yields ranging between 90-93\%). ${ }^{20}$ Referenced reaction times when using palladium nanoparticles in the cited supporting materials were 40 , 25, 240 and $600 \mathrm{~min}$, respectively. Other authors have reported analog reactions promoted by non-supported metallic palladium, reaching yields of $93 \%$ if extending to $5 \mathrm{~h}$ the reaction time. ${ }^{47}$

In a similar way, dispersed palladium nanoparticles on polymer matrixes have promoted carbon-carbon coupling reactions that take $c a .6 \mathrm{~h}$ with yields of $55 \% .{ }^{22}$

Solvent effects on coupling reactions catalyzed by palladium in nanometric arrays have also been studied. For example, water has been extensively used in combination with bases such as TBAB $,{ }^{45} \mathrm{~K}_{2} \mathrm{CO}_{3},{ }^{46} \mathrm{KF}^{20}$ and $\mathrm{Na}_{2} \mathrm{SO}_{4},{ }^{22}$ but these systems demand reaction times of up $6 \mathrm{~h}$ for assemblage of biphenyl systems. ${ }^{22}$

As a catalyst for different C-C coupling reactions of the type Heck and Suzuki, particularly for the syntheses of biphenyl, 3-nitrobiphenyl and cinnamic acid, supported palladium nanoparticles using solid zinc hydroxide acetate $\left(\right.$ LHS-Pd ${ }^{0}$ ) proved to have a series of advantages over other palladium-based systems. Excellent results are obtained when using LHS-Pd ${ }^{0}$ in terms of a significant favorable balance between yields, mild reaction conditions and proportions of active phase (1.1 mmol of Pd). Biphenyl is obtained with $98 \%$ yield in a mixture water:dioxane $(5: 1 \mathrm{v} / \mathrm{v})$ as a solvent and $\mathrm{KOH}$ as the base in $1 \mathrm{~h}$ (Table 1). Other authors report similar reaction yields, but using higher temperatures and longer reaction times..$^{22,46}$ Under the same reaction conditions, $62 \%$ yield is reached for the synthesis of 3-nitrobiphenyl. The difference between the percentages of conversion to biphenyl and 3-nitrobiphenyl is not itself associated to the catalytic system but it is attributed to the intrinsic electronic nature of the starting boronic acids. It is well known that the boronic acids undergo an electrophilic substitution in the transmetallation step of the catalytic cycle in such a way that the palladium catalyst displaces the boronic moiety, with the aromatic-ring behaving as the nucleophile and the palladium species behaving as the electrophile. The strong electron-withdrawing effect of the nitro group deactivates the ring for this step giving rise to overall acceptable reaction results.

On the other hand, the same LHS-Pd ${ }^{0}$ catalytic system for the reaction of acrylic acid and iodobenzene allowed us to obtain cinnamic acid with higher yields than the ones typically reached under the homogeneous phase conditions starting from acetic acid and benzaldehyde. In fact, it was prepared in this article cinnamic acid with $75 \%$ yield and $1.5 \mathrm{~h}$ of reaction time, in a clear contrast with the already mentioned homogeneous phase condition that demands reaction times ranging between 8 and $16 \mathrm{~h}$ and giving rise to yields of 64 to $70 \%$. The percent of yield for each run was estimated as equation 1 :

Yield $(\%)=\frac{\text { Weight of organic product }}{\text { Expected (theoretic) stoichiometric yield }} 100$

Our results of the described coupling reactions, which were carried out with the reduced LHS-Pd ${ }^{0}$ material under heterogeneous phase, comprise some evidence of the advantages of this methodology in comparison to the analog syntheses under homogeneous phase that have been reported by Simonyan. ${ }^{48}$

A schematic representation of our LHS-Pd ${ }^{0}$ material is presented in Figure 5, which is a reasonable picture that accounts for the characterization results and explains how the carbon-carbon coupling reactions are easily promoted by this nanometric array of metal palladium (see Table 1).

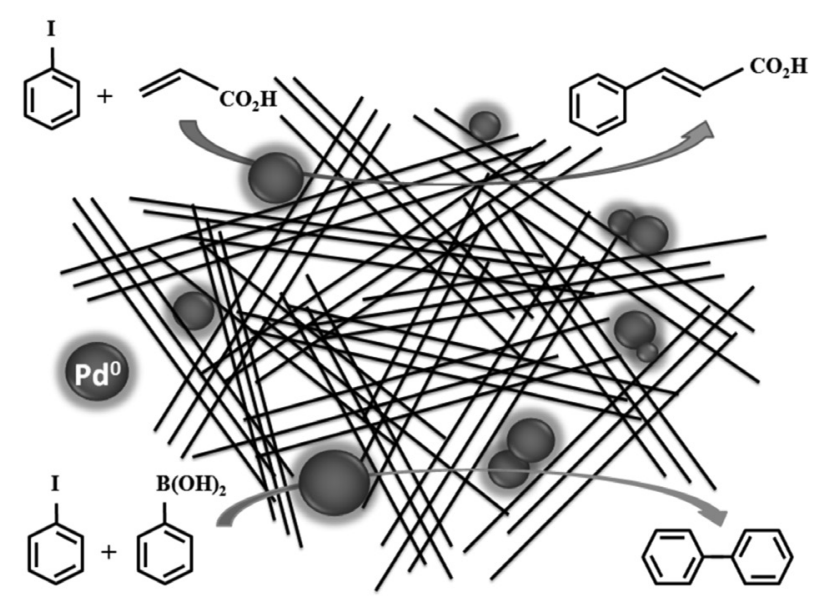

Figure 5. Schematic representation of the material LHS-Pd ${ }^{0}$.

\section{Conclusions}

It is reported the successful preparation and characterization of palladium nanoparticles supported in zinc hydroxide acetate. This was carried out by intercalation of $\left[\mathrm{PdCl}_{6}\right]^{2-}$ and its further reduction to $\mathrm{Pd}^{0}$. The size of the particles ranged between 6 and $13 \mathrm{~nm}$ as it was shown by transmission electronic microscopy. The coexistence of two different interlayer spaces was observed, being this phenomenon explained in terms of the presence of phases with a different extent of hydration. Additionally, the generation of zinc hydroxide chloride during the reduction process was also observed. 
Being constituted by supported Pd nanoparticles, this new material was used in preliminary tests to promote the synthesis of cinnamic acid, 3-nitrobiphenyl and biphenyl, with yields of 75, 62 and 97\%, respectively. It is proved that in this way the new material holds an important potential for carbon-carbon coupling organic reactions.

\section{Acknowledgements}

We greatly acknowledge and thank to Universidad de Caldas and Universidad Nacional de Colombia (Manizales) and their respective research management offices (Vicerrectoría de Investigaciones y Postgrados and Dirección de Investigaciones sede Manizales DIMA) for the financial support of this research. We also acknowledge and thank to the chemistry laboratory at Universidad Nacional de Colombia (Manizales) and its laboratories of advanced microscopy, and advanced magnetism and materials for the atomic absorption analyses, UV-Vis spectra, SEM and TG/DTG analyses. Finally, thanks to Universidad del Cauca (Colombia) for the TEM analyses.

\section{References}

1. Morioka, H.; Tagaya, H.; Karasu, M.; Kadokawa, J. I.; Chiba, K.; Inorg. Chem. 1999, 38, 4211.

2. Kandare, E.; Hossenlopp, J. M.; J. Phys. Chem. B. 2005, 109, 8469.

3. Ay, A. N.; Zümreoglu-Karan, B.; Temel, A.; Mafra, L.; Appl. Clay Sci. 2011, 51, 308; Kovanda, F.; Kovacsova, E.; Kolousek, D.; Collect. Czech. Chem. Commun. 1999, 64, 1517; Marangoni, R.; Pereira, L. P.; Wypych, F.; J. Colloid Interface Sci. 2009, 330, 303.

4. Cursino, A. C. T.; Gardolinski, J. E. F. C.; Wypych, F.; J. Colloid Interface Sci. 2010, 347, 49; Machado, G. S.; Arizaga, G. G. S.; Wypych, F .; Nakagaki, S.; J. Catal. 2010, 274, 130.

5. Qui, J.; Villemure, G.; J. Electroanal. Chem. 1997, 428, 165.

6. Moneyron, J. E.; de Roy, A.; Besse, J. P.; Solid State Ionics 1991, 46, 175.

7. Cooper, S.; Dutta, P. K.; J. Phys. Chem. 1990, 94, 114.

8. Arizaga, G. G. C.; Satyanarayana, K. G.; Wypych, F.; Solid State Ionics 2007, 178, 1143.

9. Crepaldi, E. L.; Pavan, P. C.; Valim, J. B.; J. Mater. Chem. 2000, 10, 1337.

10. Lin, M. S.; Sun, P.; Yu, H. Y.; J. Formos. Med. Assoc. 1998, 97 , 704.

11. Bruschini, C. S.; Hudson, M. J.; Access in Nanoporous Materials; Pinnavaia, T. J.; Thorpe, M. F., eds.; Plenum Press: New York, 1995, p. 161.

12. Meyn, M.; Beneke, K.; Lagaly, G.; Inorg. Chem. 1993, 32, 1209.
13. Poul, L.; Jouini, N.; Fiévet, F.; Chem. Mater. 2000, 12, 3123; Allmann R. Z.; Kristallogr. 1968, 126, 117; Stahlin, W.; Oswald, R.; Acta Cryst. 1970, B26, 860.

14. Luo, C.; Zhang, Y.; Wang, Y.; J. Mol. Catal. A: Chem. 2005, $229,7$.

15. Li, P.; Wang, L.; Li, H.; Tetrahedron 2005, 61, 8633.

16. Domínguez, S.; Berenguer, Á.; Linares, Á.; Cazorla, D.; J. Catal. 2008, 257, 87.

17. Tronto, J.; Leroux, F.; Dubois, M.; Taviot, C.; Valim, J. B.; J. Phys. Chem. Solids 2006, 67, 978.

18. Nicolaou, K. C.; Bulger, P. G.; Sarlah, D.; Angew. Chem., Int. Ed. 2005, 44, 4442 .

19. Tamami, B.; Ghasemi, S.; J. Mol. Catal. A: Chem. 2010, 322, 98.

20. Choudary, B. M.; Madhi, S.; Chowdari, N. S.; Kantam, M. L.; Sreedhar, B.; J. Am. Chem. Soc. 2002, 124, 14127.

21. Narayanan,R.;El-Sayed,M.A.;J.Am.Chem. Soc. 2003, 125, 8340.

22. Yang, X.; Fei, Z.; Zhao, D.; Han Ang, W.; Li, Y.; Dyson, P. J.; Inorg. Chem. 2008, 47, 3292;

23. Gniewek, A.; Ziólkowski, J. J.; Trzeciak, A. M.; Zawadzki, M.; Grabowska, H.; Wrzyszcz, J.; J. Catal. 2008, 254, 121.

24. Evangelisti, C.; Panziera, N.; Pertici, P.; Vitulli, G.; Salvadori, P.; Battocchio, C.; Polzonetti, G.; J. Catal. 2009, 262, 287.

25. Polshettiwar, V.; Hesemann, P.; Moreau, J. J. E.; Tetrahedron 2007, 63, 6784 .

26. Athilakshmi, J.; Ramanathan, S.; Chand, D. K.; Tetrahedron Lett. 2008, 49, 5286.

27. Söderberg, B. C. G.; Coord. Chem. Rev. 2003, 241, 147.

28. Bringmann, G.; Ochse, M.; Götz, R.; J. Org. Chem. 2000, 65, 2069.

29. Dounay, A. B.; Overman, L. E.; Chem. Rev. 2003, 103, 2945.

30. Phan, N. T. S.; Van Der Sluys, M.; Jones, C. W.; Adv. Synth. Catal. 2006, 348, 609.

31. Danishefsky, S. J.; Masters, J. J.; Young, W. B.; Link, J. T.; Snyder, L. B.; Magee, T. V.; Jung, D. K.; Isaacs, R. C. A.; Bornmann, W. G.; Alaimo, C. A.; Coburn, C. A.; Di Grandi, M. J.; J. Am. Chem. Soc. 1996, 118, 2843.

32. Häberli, A.; Leumann, C. J.; Org. Lett. 2001, 3, 489.

33. Masters, J. J.; Jung, D. K.; Bornmann, W. G.; J, S.; Danishefsky, S. D. G.; Tetrahedron Lett. 1993, 34, 7253.

34. Narasimhan, B.; Belsare, D.; Pharande, D.; Mourya, V.; Dhake,A.; Eur. J. Med. Chem. 2004, 39, 827.

35. Letizia, C. S.; Cocchiara, J.; Lapezynsky, A.; Lalko, J.; Api, A. M.; Food Chem. Toxicol. 2005, 43, 925.

36. Zhu, L.; Patel, M.; Zhang, M.; Tetrahedron Lett. 2008, 49, 2734.

37. Rajamathi, J. T.; Ahmed, M. F.; Ravishankar, N.; Nethravathi, C.; Rajamathi. M.; Solid State Sci. 2009, 11, 1270.

38. Smart, L. E.; Moore, E. A.; Solid State Chemistry: An introduction, $3^{\text {rd }}$ ed.; CRC Press: Boca Raton, 2005, p. 33487; American Public Health (APHA); Standard Methods for the Examination of Water and Wastewater, $21^{\text {st }}$ ed.; American Public Health Association: Washington DC, 2005, p. 4500. 
39. Morioka, H.; Tagaya, H.; Kadokawa, J. I.; Chiba, K.; J. Mater. Sci. Lett. 1999, 18, 995.

40. Hosono, E.; Fujihara, S.; Kimura, T.; Imai, H.; J. Colloid Interface Sci. 2004, 272, 391.

41. Song, R.-Q.; Xu, A.-W.; Deng, B.; Li, Q.; Chen, G.-Y.; Adv. Funct. Mater. 2007, 17, 296.

42. Data Collection of the Joint Committee on Powder Diffraction Standard, PDF-number: 07-0155. (CD).

43. Data Collection of the Joint Committee on Powder Diffraction Standard, PDF-number: 65-2867. (CD).
44. Cavani, F.; Trifirò, F.; Vaccari, A.; Catal. Today. 1991, 11, 173.

45. Zhang, Z.; Wang, Z.; J. Org. Chem. 2006, 71, 7485.

46. Chandrasekhar, V.; Narayanan, R. S.; Thilagar, P.; Organometallics 2009, 28, 5883.

47. Alonso, F.; Beletskaya, I. P.; Yus, M.; Tetrahedron 2005, 61, 11771.

48. Simonyan, A. V.; Pharm. Chem. J. 1999, 33, 158.

Submitted: March 30, 2011 Published online: September 20, 2011 